\title{
PENERAPAN KONSEP ARSITEKTUR SEMIOTIKA PADA BANGUNAN MASJID AL - IRSYAD SATYA
}

\author{
${ }^{1}$ Eka Fajar Nugraha, ${ }^{2}$ Ashadi \\ 1-2Fakultas Teknik, Universitas Muhammadiyah Jakarta, Jakarta, \\ ekafajarn@gmail.com ${ }^{1}$
}

\author{
Informasi Naskah \\ Diterima: 16/09/2020; Disetujui terbit: 29/12/2020; Diterbitkan: 29/12/2020; \\ http://journal.uib.ac.id/index.php/jad
}

\begin{abstract}
ABSTRAK
Kajian ini membahas penerapan arsitektur semiotika pada bangunan Masjid. Semiotika dalam arsitektur merupakan bahasa simbol yang memberi dan memahami informasi kepada pengamat lewat bentuk-bentuk dan pesan tertentu. Hal yang melatarbelakangi pentingnya kajian ini adalah proses pemaknaan sebuah bangunan yang ingin di sampaikan, setidaknya akan mampu dihayati oleh masyarakat umum dan pengamat bangunan. Penelitian ini bertujuan untuk mengetahui bagaimana penerapan tanda berdasarkan semiotika Peirce: Ikon, Indeks, dan Simbol pada bangunan Masjid Al- Irsyad Satya. Metode yang digunakan adalah kualitatif deskriptif, yaitu dengan mengamati fenomena secara lebih rinci tentang keadaan bangunan Masjid Al-Irsyad Satya yang dianggap sebagai tanda. Hasil penelitian ini menunjukkan bahwa Masjid Al-Irsyad Satya termasuk yang menerapkan konsep Arsitektur Semiotika dengan klasifikasi berdasarkan Ikon, Indeks, dan Simbol.
\end{abstract}

Kata Kunci: Ikon, Indeks, Semiotika, Simbol, Tanda

\begin{abstract}
This study discusses the application of semiotic architecture in mosque buildings. Semiotics in architecture is a symbolic language that provides and understands information to observers through certain forms and messages. The background to the importance of this study is the process of interpreting a building that you want to convey, at least it will be able to be lived by the general public and building observers. This study aims to determine how the application of signs based on Peirce's semiotics: Icons, Indices, and Symbols in the building of the Al-Irsyad Satya Mosque. The method used is descriptive qualitative, by observing the phenomenon in more detail about the condition of the Al-Irsyad Satya Mosque building which is considered a sign. The results of this study indicate that the Al-Irsyad Satya Mosque is one of those that applies the concept of semiotic architecture with a classification based on icons, indexes, and symbols.
\end{abstract}

Keywords: icons, indices, semiotics, symbols, signs

\section{Pendahuluan}

Dalam perkembangan karya arsitektur, konsep semiotika mulai banyak digunakan sejak era konsep arsitektur post-modern dimana para arsitek berkeinginan mengajak masyarakat awam untuk memahami karyanya dengan cara menyampaikan pesan di dalam bentuk bangunan, baik gagasan, ideologi atau pesan yang terbentuk dari elemen-elemen arsitektur bangunannya, sehingga membentuk suatu tanda di dalam bangunannya (interior) maupun di luar bangunannya (eksterior).

Semiotika memiliki kaitan yang erat dalam kehidupan manusia, hal ini karena semiotika merupakan ilmu yang mengkaji suatu tanda. Semua yang hadir dalam kehidupan manusia dilihat sebagai tanda, yakni sesuatu yang harus diberi makna. Tujuan dari semiotika adalah memahami kemampuan otak manusia untuk memproduksi dan 
memahami tanda serta kegiatan membangun pengetahuan tentang sesuatu dalam kehidupan manusia. (Muktiono, Tinjauan Semiotika Pada Masjid Jakarta Islamic Center, 2019).

Semiotika arsitektur mengajak kita untuk merenungkan berbagai hal yang terkait dalam bentuk arsitektur, dapat terlihat pada tampilan visual fasad bangunan yang dimana terdapat tanda atau simbol arsitektur dalam bentuk ragam hias maupun elemen arsitektur bangunan yang perlu dikaji dengan menelusuri bagaimana bentuk tersebut (semantik), hubungan bentuk (sintaksis), dan makna dari bentuk (pragmatik). Kajian relasi tanda visual menggunakan semiotika arsitektur sebagai upaya menterjemahkan bahasa tanda pada karya arsitektur. (Muktiono, Tinjauan Semiotika Pada Masjid Jakarta Islamic Center, 2019)

Dalam kajian Penerapan Konsep Semiotika pada bangunan-bangunan yang ada di Indonesia khususnya bangunan Masjid, hal yang harus di pelajari oleh arsitek dalam merancang bangunan masjid selain mengedepankan suatu keindahan pada bentuk atau fasad bangunan harus bisa juga menyampaikan bahwa dalam merancang bangunan masjid ada unsur makna atau pesan yang bisa di pahami oleh masyarakat pada umumnya.

Kajian ini bertujuan untuk memahami klasifikasi menurut Pierce dan menelusuri bangunan-bangunan di indonesia khususnya bangunan masjid yang menerapkan konsep arsitektur semiotika.

\section{Kajian Pustaka}

Penggunaan konsep semiotika pada bangunan masjid, sebenarnya sudah di terapkan di Indonesia oleh para perancangnya, hal ini karena bangunan masjid mempunyai arti dan makna di dalam bangunannya. Agar lebih memahami mengenai pengertian arsitektur semiotika, maka ada beberapa definisinya antara lain:

\subsection{Semiotika Arsitektur}

Semiotika merupakan ilmu yang mempelajari bagaimana cara mengidentifikasi tanda dan simbol (Cobley \& Jansz, 2002). Di dalam semiotika arsitektur terdapat tiga kategori hubungan tanda dengan unsur dalam arsitekturnya yaitu sintaksis, pragmatik, dan semantik. Jika dalam bidang sastra yang menjadi pusat perhatian adalah "kata bahasa" sedangkan dalam bidang arsitektur yang menjadi pusat perhatian adalah "elemen visual dan spasial" (Zahnd, 2009).

Secara etimologis semiotik berasal dari kata Yunani simeon yang berarti "tanda". Secara terminologis, semiotik dapat didefinisikan sebagai ilmu yang mempelajari sederetan luas objek-objek, peristiwa-peristiwa seluruh kebudayaan sebagai tanda. Van Zoest (dalam Sobur, 2001) mengartikan semiotik sebagai ilmu "tanda" (sign). (Ramdani, 2016).

Tanda merupakan sebuah pondasi dasar dalam ilmu semiotika, dimana unsur-unsur tersebut mencakup segala sesuatu yang berhubungan dengan makna atau arti, tanda memiliki dua kategori yakni sebagai penanda (bentuk, ikon,simbol,) dan sebagai petanda (makna/arti). Dalam Kamus Besar Indonesia tanda berupa sebuah bentuk komunikasi yang menunjukkan suatu, gejala,bukti,pengenal, dan petunjuk. (Ningrum, 2014).

\subsection{Tanda Dalam IImu Arsitektur}

Klasifikasi tanda dalam ilmu semiotika menurut Pierce (dalam Dariwu dan Rengkung, 2010) semiotika sangat berhubungan dengan denotatum atau lebih dikenal dengan 
(objek), dimana tanda dibagi menjadi "ikon, indeks, dan simbol", semiotika juga berkaitan dengan ground, tanda dibagi menjadi "qualisin, sinsign dan legisign". (Ningrum, 2014). Dari pernyataan di atas, klasifikasi tanda dalam semiotika menurut Pierce adalah:

a. Ikon adalah tanda yang menyerupai objek (benda) atau berupa kemiripan. Misalnya sketsa wajah merupakan menggambarkan dirinya.

b. Indeks adalah hubungan antar tanda, dimana tanda memiliki hubungan yakni sebab akibat. Misalnya pintu merupakan alat untuk masuk, jadi jika ingin masuk harus memiliki pintu.

c. Simbol/lambang adalah tanda yang sudah ada, terbentuk secara konvensional atau sebuah kesepakatan bersama, simbol atau lambang menggambarkan suatu peraturan yang berlaku.

d. Qualisign yakni kualitas yang ada pada tanda, dimana tanda yang menjadi tanda berdasarkan sifatnya.

e. Sinsign adalah klasifikasi tanda yang berdasarkan kepada kejadian atau suatu peristiwa, bentuk atau rupanya yang khas.

f. Legisign adalah klasifikasi tanda yang terkandung norma atau terdapat hukum tertentu yang melatar belakangi sebuah tanda.

Dalam ilmu semiotika khususnya dalam tahap pemaknaan melalui penulusuran makna Pierce menggunakan dua jenis makna yakni makna denotif dan makna konotatif, dimana makna denotif menggunakan tanda-tanda visual yang terlihat, seperti warna, tekstur, bentuk dan bidang. Tahap penelusuran makna melalui tanda-tanda yang terlihat dianggap sebagi informasi tanda yang utama (Noth,1995). (Ningrum, 2014). Dalam arsitektur setiap tanda mempunyai komponen yang indikatif (bersifat menyatakan). Misalnya :

a. Panah, menunjukan arah atau sirkulasi

b. Pintu kaca, menyatakan dirinya sendiri dan apa yang ada dibelakangnya

c. Jendela, menunjukan hubungan dalam dan luar.

d. Lingkup tapak, berupa pedestrian, paving blok, atau lanskap yang menunjukan arah atau sirkulasi manusia

e. Dalam lingkup bangunan, berupa elemen-elemen yang menujukan tertentu didalamnya seperti tangga (indeks ruang utama).

f. Bentuk ornamen dan hiasan pada bagian bangunan.

Semua unsur ini merupakan tanda-tanda yang berhubungan dengan suatu keadaan yang nyata. Dengan melihatnya akhirnya timbul suatu kesimpulan dari peneliti bahwa banguan ini dimaksudkan untuk sekolah, untuk rumah sakit, dan sebagainya. Atau dalam bangunan bisa menunjukan ruang-ruang tertentu di dalamnya, seperti pintu besar (indeks ruang utama), kubah (indeks ruang utama), bagian dinding yang menjorok keluar (indeks mihrab).

\section{Metode Penelitian}

Penelitian ini akan menggunakan metode kualitatif deskriptif yaitu penelitian dengan mengamati fenomena secara lebih rinci tentang suatu keadaan. Dalam melakukan peneletian akan dilakukan dalam beberapa tahap yaitu: tahap pengambilan data, tahap pengumpulan data, tahap analisis data, dan tahap penarikan kesimpulan.

Materi yang dibutuhkan dalam penelitian ini berkaitan dengan Bangunan Masjid. Data-data yang akan diteliti berupa data fisik. Data fisik merupakan data yang dapat 
dirasakan langsung oleh pengamat,yang termasuk data fisik dalam penelitian ini, yaitu :

1. Fasad Bangunan

2. Menara Masjid

3. Pedestrian

4. Landscape

5. Elemen - elemen yang menunjukan ruang tertentu seperti tangga, pintu besar, kubah, dan dinding ang menjorok ke luar (mihrab)

\section{Ornamen}

7. Hiasan

Materi yang dibutuhkan dalam penelitian ini dikhususkan pada Bangunan Masjid, penerapan arsitektur Semiotika pada Bangunan Masjid seperti yang sudah dijelaskan sebelumnya. Pada kajian ini peneliti akan menggunakan teori Semiotika yang berpengaruh pada Bangunan tersebut.

\subsection{Objek Penelitian}

Objek penelitian ini adalah bangunan masjid Al-Irsyad Satya yang terletak di jalan Parahyangan KM. 27 Kota Baru Parahyangan, Cipeundeuy, Padalarang, Kabupaten Bandung Barat, Jawa Barat.

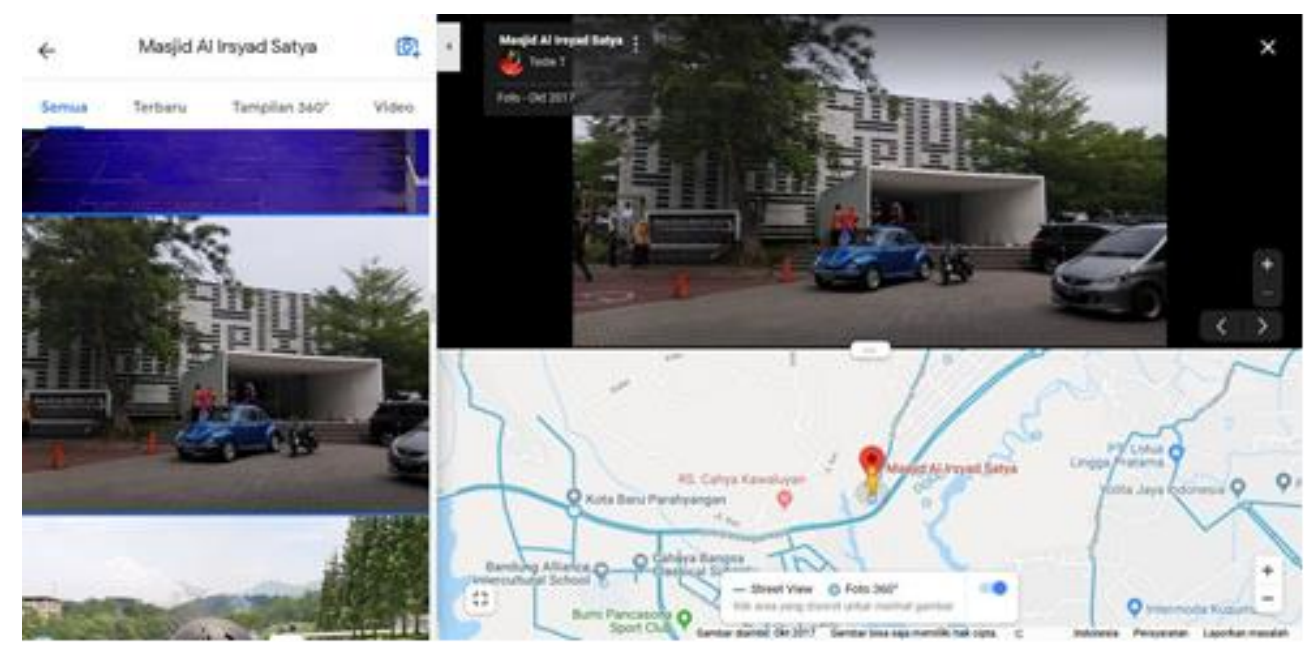

Gambar 1. Peta lokasi masjid Al-Irsyad Satya Sumber: google.com/maps, 2020

\section{Hasil dan Pembahasan}

Hasil analisis klasifikasi tanda arsitektur semiotika terhadap hasil studi kasus pada bangunan masjid Al-Irsyad Satya Yaitu :

\section{Desain bangunan mengutamakan bentuk dan elemen-elemen bangunan}

Mesjid Al-Irsyad Satya berbentuk berupa kubus sederhana terinspirasi oleh Ka'bah yang ada di Masjidil Haram. Fasad Masjid merupakan susunan concrete block yang membentuk kaligrafi kalimat As-Syahadah. Lanskap dan ruang terbuka, dirancang berbentuk garis-garis melingkar yang mengelilingi bangunan terinspirasi dari konsep tawaf yang mengelilingi Ka'bah.

a. Gambaran Umum

Masjid Al-Irsyad di bangun pada tanggal 7 September 2009 bertepatan dengan 17 ramadhan $1930 \mathrm{H}$ (Nuzulul Qur'an), dan di resmikan pada bulan agustus 2010. 
b. Elemen Bangunan Masjid Al-Irsyad

- Bentuk bangunan

Bentuk masjid Al-Irsyad kubus seperti bangunan Ka'bah, selain itu dinding Masjid di buat celah angin dengan tulisan kaligrafi kufi yang di aplikasikan dengan material conblock (dapat dilihat pada gambar 2).

- Tampak depan masjid Al-Irsyad

Tampak bangunan masjid Al-Irsyad kubus di desain membentuk tulisan kaligrafi kufi agar udara dari luar masuk ke dalam masjid yang di aplikasikan dengan material conblock (dapat dilihat pada gambar 3).



Gambar 2. Bentuk masjid Al-Irsyad Satya Sumber: Data Pribadi, 2020



Gambar 3. Tampak Depan Al-Irsyad Satya Sumber: Data Pribadi, 2020

- Tampak samping masjid Al-Irsyad

Tampak bangunan samping masjid Al-Irsyad tidak berbeda jauh dengan tampak depan karena dari bentuk bangunan nya kubus sehingga semua sisinya sama (dapat dilihat pada gambar 4). 


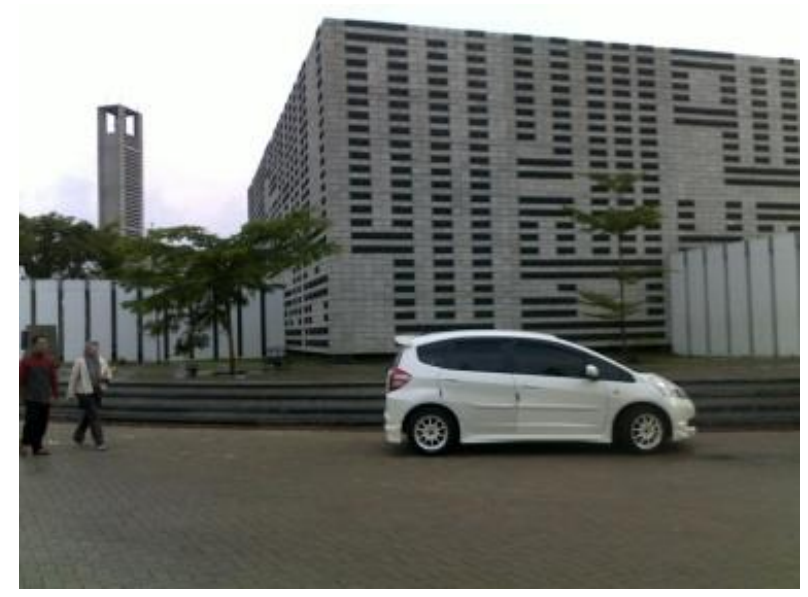

Gambar 4. Tampak Samping Al-Irsyad Satya Sumber: Data Pribadi, 2020

- Elemen Pencahayaan

Pencahayaan ruang utama sholat masjid Al-irsyad (dapat dilihat pada gambar 5) memiliki makna yang terkandung dari sifat-sifat Allah SWT (Asmaul Husna).

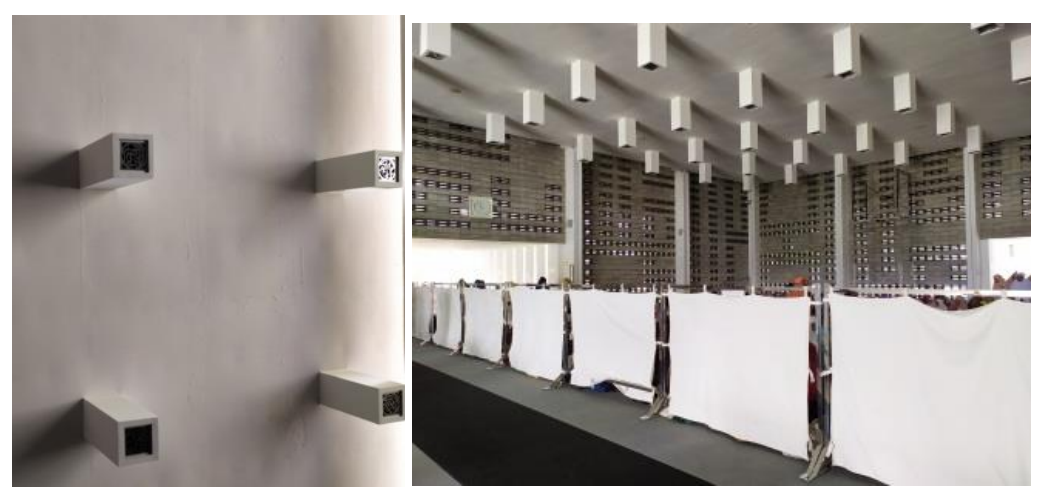

Gambar 5. Elemen Lampu Pencahayaan

Sumber: Data pribadi, 2020

\section{- Pedestrian}

Pedestrian yang merupakan bagian luar dari bangunan masjid di desain mengelilingi bangunan masjid agar terlihat sedang melaksanakan ibadah Thawah (dapat dilihat pada gambar 6).

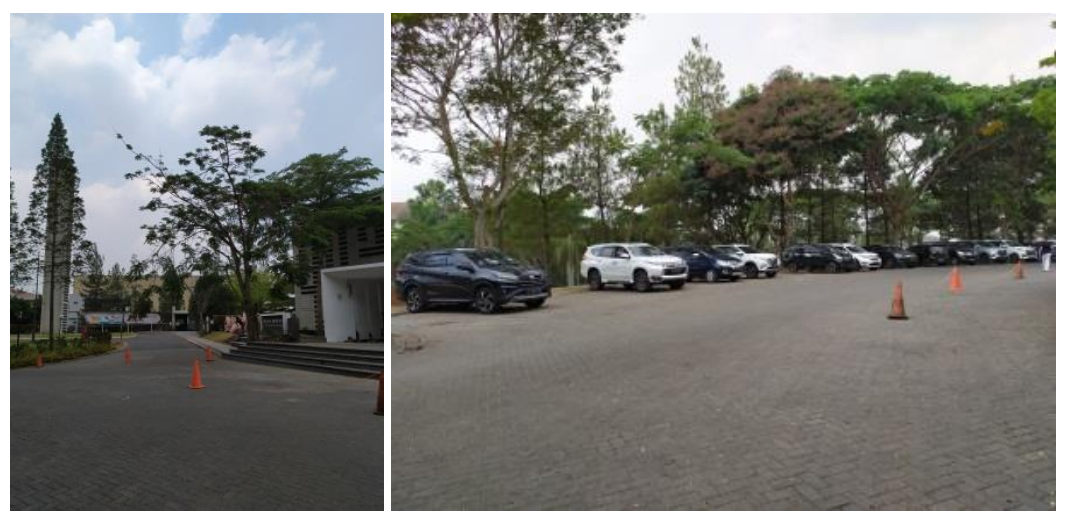

Gambar 6. Pedestrian Masjid Al-Irsyad Sumber: Data pribadi, 2020 
- Menara Mesjid

Menara pada masjid Al-Irsyad di desain untuk menandakan keberadaan bangunan masjid di wilayah tersebut, selain itu menara masjid di fungsikan sebagai tempat untuk pengeras suara adzan mengingatkan untuk beribadah sholat 5 waktu (dapat dilihat pada gambar 7).

- Bola Bulat Lafad Allah

Bola Bulat yang bertuliskan lafad Allah SWT ditempatkan di tengah mihrab untuk memberitahukan kepada masyarakat bahwa batu ini merupakan simbol untuk mencegah orang lewat di depan imam masjid (dapat dilihat pada gambar 8).


Gambar 7. Menara Masjid Al-Irsyad Sumber: Data pribadi, 2020

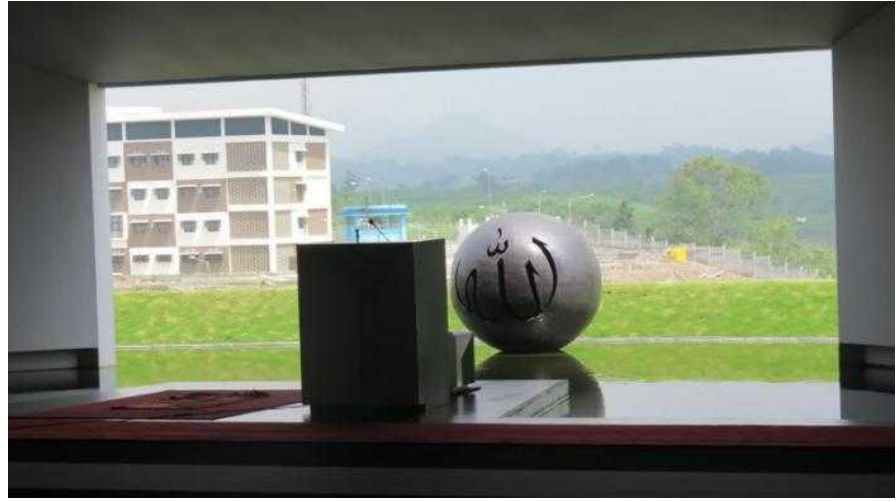

Gambar 8. Bola Bulet Masjid Al-Irsyad Sumber: Data pribadi, 2020

\section{Analisis penerapan Klasifikasi Tanda pada Masjid Al-Irsyad Satya}

\section{- Bentuk Bangunan}

Pada bangunan Masjid Al-Irsyad Satya menerapkan arsitektur semiotika dengan usur tanda ikon. Ikon adalah tanda yang menyerupai objek (benda) atau berupa kemiripan. Analisis bentuk bangunan masjid Al-Irsyad Satya membentuk ikon bangunan ka'bah artinya tempat yang suci. Ka'bah merupakan sebuah kiblat atau patokan yang dijadikan arah shalat untuk umat muslim di seluruh dunia. Bentuk Ka'bah berbentuk bujur sangkar yang merupakan bentukan sempurna untuk sebuah barisan shalat yang artinya dapat dengan mudah meluruskan shaf dari depan ke belakang (dapat dilihat pada gambar 9). 

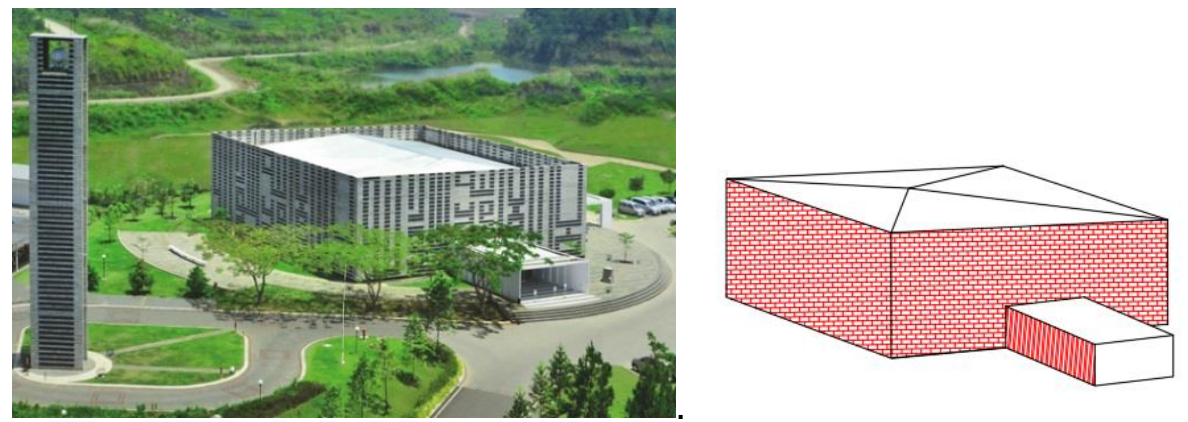

Gambar 9. Analisis Klasifikasi Ikon Ka'bah Sumbe : Data pribadi, 2020

\section{- Menara}

Menara pada masjid merupakan salah satu unsur tanda indeks yang memiliki hubungan antar tanda, dimana tanda memiliki hubungan sebab akibat. Analisis menara bangunan masjid Al-Irsyad Satya berfungsi untuk menyebarkan doa azan dengan memperingatkan umat Muslim agar bersholat, baik lewat speaker atau lewat suara langsung, jadi ketika mendengar azan maka bersumber dari menara masjid (dapat dilihat pada gambar 10).
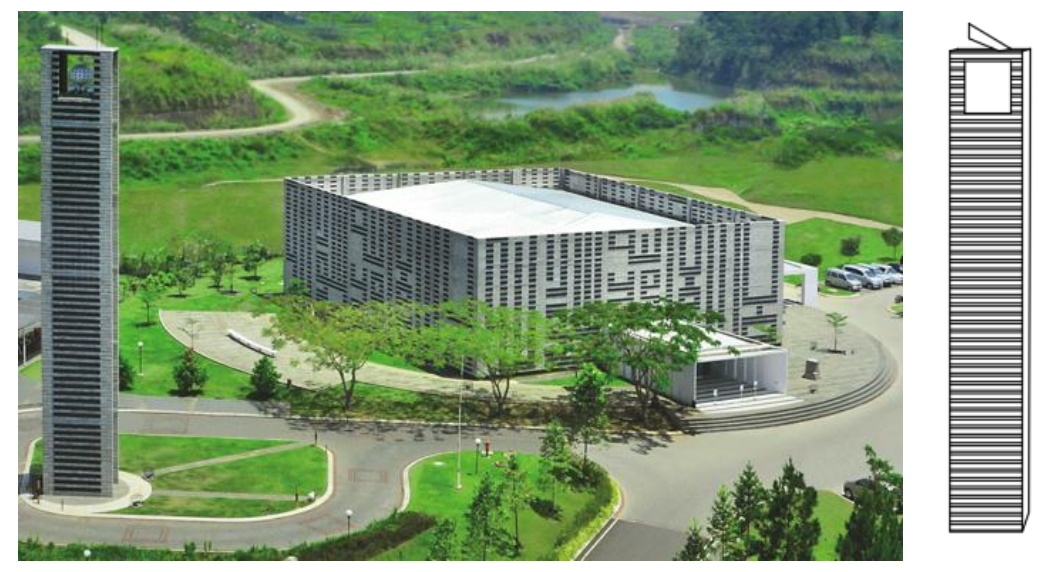

Gambar 10. Analisis Klasifikasi Indeks Menara Sumber: Data pribadi, 2020

\section{- Tangga}

Unsur tanda indeks pada tangga masjid Al-Irsyad Satya untuk penghubung sirkulasi antar lantai bangunan bertingkat dengan berjalan naik atau turun menggunakan trap (anak tangga). Penerapan unsur tanda indeks sebagai penghubung lantai yang berbeda terlihat pada tangga (dapat dilihat pada gambar 11). 


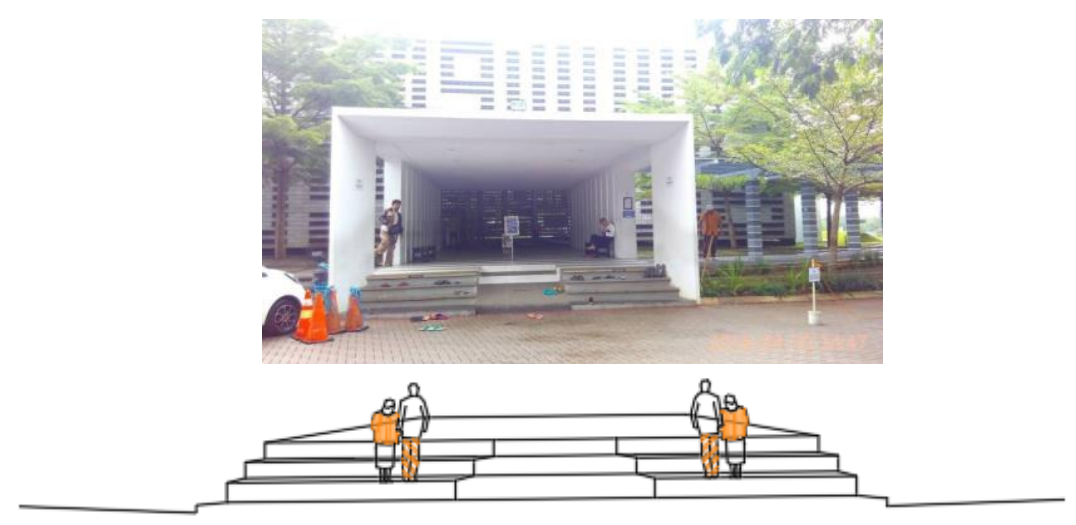

Gambar 11. Analisis Klasifikasi Indeks Tangga Sumber : Data pribadi, 2020

- Gate Entrance

Gate Entrance masjid Al-Irsyad Satya membentuk tanda Indeks, karena menampakkan bagian dari pintu utama masjid Al-Irsyad Satya untuk memasuki ke ruangan utama sholat. Penerapan unsur tanda indeks pada gate entrance sebagai pintu utama untuk masuk kedalam masjid, jadi ketika mau masuk masjid harus melewati pintu utama (dapat dilihat pada gambar 12).


Gambar 12. Analisis Klasifikasi Indeks Gate Entrance Sumber: Data pribadi, 2020

- Mihrab

Klasifikasi tanda indeks pada mihrab mesjid befungsi sebagai tempat imam berdiri menghadap kiblat untuk memimpin sholat jama'ah. Mihrab masjid Al-Irsyad Satya memperlihatkan pada bagian dindingnya yang menjorok dan membentuk gate yang memperlihatkan tanda tempat sholatnya imam masjid (dapat dilihat pada gambar 13).
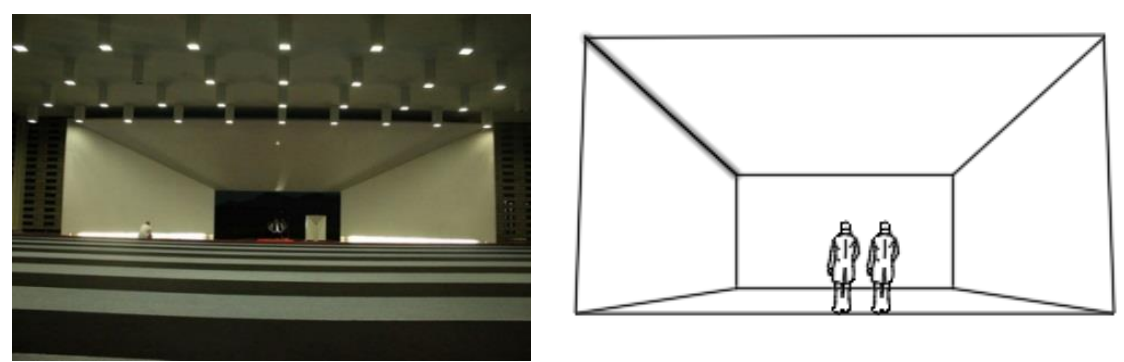

Gambar 13. Analisis Klasifikasi Indeks Mihrab Sumber: Data pribadi, 2020 
- Pedestrian

Elemen pedestrian pada masjid Al-Irsyad Satya merupakan unsur tanda indeks yang berfungsi sebagai arah sirkulasi manusia dengan mengintruksikan kepada pengguna jalan dan kepada para pengunjung, untuk berjalan ke dalam masjid (dapat dilihat pada gambar 14).

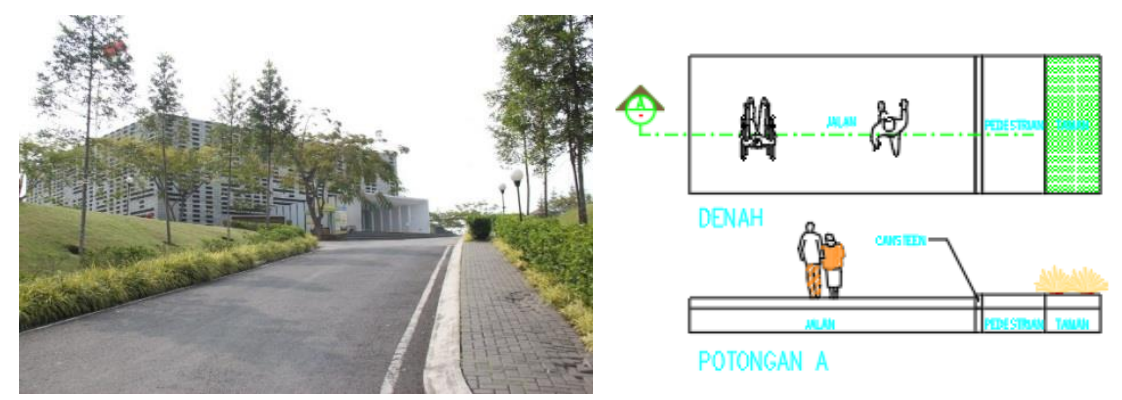

Gambar 14. Analisis Klasifikasi Indeks Pedestrian Sumber: Data pribadi, 2020

- Kaligfari Kufi

Ornamen kaligrafi Kufi di masjid Al-Irsyad sebagai klasifikasi tanda indeks yang berfungsi menyiratkan tulisan ayat suci Al-qur'an La Ilaha Illallah Muhammadur Rasulullah yang artinya tiada Tuhan Selain Allah dan Nabi Muhammad utusan Allah SWT. Adanya tulisan ayat suci alquran yang menandakan bangunan masjid menggunakan ornamen kaligrafi kufi. Bentuknya, dua kalimah tauhid yang melekat pada tiga sisi bangunan dalam bentuk susunan batu bata, yang dirancang sebagai kaligrafi tiga dimensi raksasa (dapat dilihat pada gambar 15).


Gambar 15. Analisis Klasifikasi Indeks Kaligrafi Kufi Sumber: Data pribadi, 2020

- Interior Masjid

Interior di masjid Al-Irsyad membentuk tanda Indeks, di dalam interior masjid, jumlah lampu yang dipasang sebanyak 99 buah sebagai simbol 99 nama-nama Allah atau Asmaul Husna. Masing-masing lampu yang berbentuk kotak, memiliki sebuah tulisan nama Allah. Tulisan pada lampu-lampu itu dapat dibaca secara jelas dimulai dari sisi depan kanan masjid hingga tulisan ke-99 pada sisi kiri bagian belakang masjid. Pda bangunan Masjid Al-Irsyad memiliki tiga warna yaitu putih, hitam, dan abu-abu. Susunan tiga warna tersebut menjadikan tampil lebih cantik, modern, simpel namun tetap elegan dan enak dipandang mata. Interior bangunan dibuat sangat nyaman, sehingga menambah kekhusukan dalam beribadah (dapat dilihat pada gambar 16). 

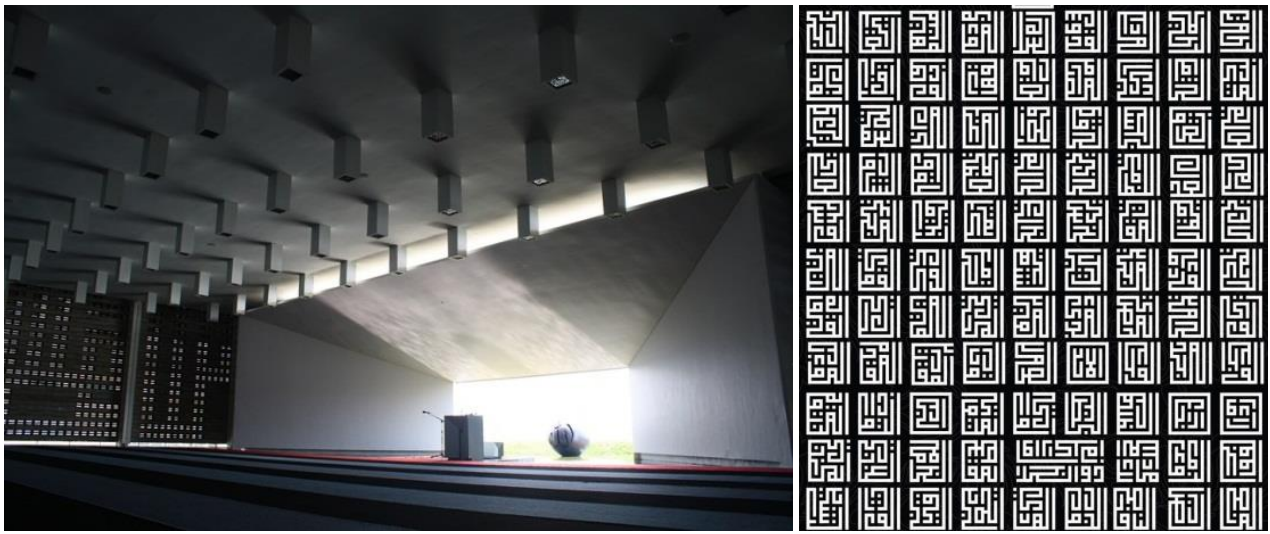

Gambar 16. Analisis Klasifikasi Indeks Interior Sumber : Data pribadi, 2020

- Bola Bulat Lafad Allah

Bola bulat bertuliskan lafad Allah di letakkan di depan mihrab imam menandakan simbol pada masjid Al-Irsyad, karena simbol bola bulat itu menginformasikan orang tidak boleh lewat ketika ada yang sedang mengerjakan sholat dan sebagai tanda arah kiblat. Suasana ruang terbuka tanpa dinding dengan pemandangan kolam ikan serta alam luas, sehingga seolah-olah berada di ruang terbuka dan suara gemericik air kolam menambah kedamaian saat melakukan sholat (dapat dilihat pada gambar 17).



Gambar 17. Analisis Klasifikasi Simbol Sumber : Data pribadi, 2020

\section{Kesimpulan}

Penerapan arsitektur semiotika dengan klasifikasi tanda pada bangunan masjid AlIrsyad Satya didapatkan hasil dari anlisa dan dapat disimpulkan bahwa :

1. Bangunan masjid Al-Irsyad Satya didesain sesuai dengan penerapan arsitektur semiotika dengan klasifikasi tanda ikon, indeks dan Simbol.

2. Tanda Ikon pada bangunan masjid Al-Irsyad Satya terlihat pada bentuk bangunannya yang menyerupai bangunan Ka'bah ( Mekkah ) yang berfungsi sebagai kiblat atau patokan yang dijadikan arah shalat untuk umat muslim di seluruh dunia. Bentuk bujur sangkar untuk sebuah barisan shalat yang artinya dapat dengan mudah meluruskan shaf dari depan ke belakang.

3. Tanda Indeks pada bangunan masjid Al-Irsyad Satya yang memiliki sebab akibat 
terdapat pada bentuk elemen yaitu : Menara Masjid, Tangga, Gate Entrance, Mihrab, Pedestrian, Kaligrafi Kufi, dan Interior Masjid.

4. Tanda simbol bola bulat bertuliskan lafad Allah di letakkan di depan mihrab imam menandakan simbol pada masjid Al-Irsyad, karena simbol bola bulat itu menginformasikan orang tidak boleh lewat ketika ada yang sedang mengerjakan sholat dan sebagai tanda arah kiblat.

5. Penggunaan komponen pada Masjid Al-Irsyad Satya sebagai tanda yang bersifat indikatif dengan menyatakan unsur arsitektur dengan fungsi dan makna yang berbeda-beda, seperti elemen, ornamen, hiasan dan pedestrian.

6. Berdasarkan identifikasi pada studi kasus bangunan masjid Al-Irsyad Satya yang diteliti adalah bangunan masjid yang mempelajari bagaimana orang bernalar, berpikir, berkomunikasi, dan memberi makna apa yang ditampilkan oleh bangunan kepada orang lain melalui tanda.

\section{Daftar Pustaka}

Dariwu, C. T., \& Rengkung, J. (2012). Kajian Semiotika Dalam Arsitektur Tradisional Minahasa. Jurnal Arsitektur neliti.com. Retrieved 10 19, 19, from https://media.neliti.com/media/publications/62038-ID-kajian-semiotoka-dalamarsitektur-tradis.pdf

Dharma, A. (2010). Semiotika Dalam Arsitektur. Retrieved 2019, from http://staffsite.gunadarma.ac.id/agus_dh/

Dharma, A. (2019, 9 22). Paradigma Konseptual Arsitektur Dekonstruksi . Retrieved from Staffsite.gunadarma.ac.id:

http://staffsite.gunadarma.ac.id/agus_dh/index.php?stateid=files\&xcat_id=0.1

Mandey, J. C. (2017). Semiotik Gereja GMIM Jemaat Pniel Bahu Manado. Media Matrasain Volume 14, No. 02.

Mayasari, M. S., Tulistyantoro, L., \& Rizqy, M. T. (2014). Kajian Semiotik Ornamen Interior Pada Lamin Dayak Kenyah. Jurnal Intra Vol. 2, No. 2.

Muktiono, A. (2018). Kajian Semiotika Arsitektur Masjid At-Tin. Jurnal IImiah Arjouna, Vol. 02, No. 02.

Muktiono, A. (2019). Tinjauan Semiotika Pada Masjid Jakarta Islamic Center. Jurnal IImiah Arjuna, Vol. 03, No. 02.

Ningrum, F. D. (2014). Kajian Semiotika Bangunan Istana Maimoon. Medan: Universitas Sumatera Utara.

Ramdani, a. H. (2016). Analisis semiotika foto bencana kabut asap. Bandung: fakultas pendidikan ilmu pengetahuan sosialuniversitas pendidikan indonesia. Retrieved from http://repository.upi.edu

Rasyidi, R. A., \& Amiuza, C. B. (2017). Semiotika Arsitektur Rumah Adat Kudus Joglo Pencu. arsitektur.studentjournal 